\title{
The Impact of Wrist Percooling on Physiological and Perceptual Responses during a Running Time Trial Performance in the Heat
}

\author{
Kelsey Denby, Ronald Caruso, Emily Schlicht and Stephen J. Ives * (10 \\ Department of Health and Human Physiological Sciences, Skidmore College, Saratoga Springs, NY 12866, USA; \\ kdenby@skidmore.edu (K.D.); rcaruso@skidmore.edu (R.C.); eschlich@skidmore.edu (E.S.) \\ * Correspondence: sives@skidmore.edu; Tel.: +1-518-580-8366
}

Received: 23 September 2020; Accepted: 15 October 2020; Published: 17 October 2020

check for updates

\begin{abstract}
Environmental heat stress poses significant physiological challenge and impairs exercise performance. We investigated the impact of wrist percooling on running performance and physiological and perceptual responses in the heat. In a counterbalanced design, 13 trained males ( $33 \pm 9$ years, $15 \pm 7 \%$ body fat, and maximal oxygen consumption, $\mathrm{VO}_{2} \max 59 \pm 5 \mathrm{~mL} / \mathrm{kg} / \mathrm{min}$ ) completed three $10 \mathrm{~km}$ running time trials $\left(27^{\circ} \mathrm{C}, 60 \%\right.$ relative humidity) while wearing two cooling bands: (1) both bands were off (off/off), (2) one band on (off/on), (3) both bands on (on/on). Heart rate (HR), HR variability (HRV), mean arterial pressure (MAP), core temperature $\left(\mathrm{T}_{\mathrm{CO}}\right)$, thermal sensation (TS), and fatigue (VAS) were recorded at baseline and recovery, while running speed (RS) and rating of perceived exertion (RPE) were collected during the $10 \mathrm{~km}$. Wrist cooling had no effect $(p>0.05)$ at rest, except modestly increased HR $(3-5 \Delta$ beats $/ \mathrm{min}, p<0.05)$. Wrist percooling increased $(p<0.05)$ RS $(0.25 \Delta \mathrm{mi} / \mathrm{h})$ and HR (5 $\Delta$ beats $/ \mathrm{min})$, but not $\mathrm{T}_{\mathrm{CO}}\left(\Delta 0.3{ }^{\circ} \mathrm{C}\right)$, RPE, or TS. Given incomplete trials, the distance achieved at $16 \mathrm{~min}$ was not different between conditions (off/off $1.96 \pm 0.16 \mathrm{vs}$. off/on $1.98 \pm 0.19$ vs. on/on $1.99 \pm 0.24$ miles, $p=0.490$ ). During recovery HRV, MAP, or fatigue were unaffected $(p>0.05)$. We demonstrate that wrist percooling elicited a faster running speed, though this coincides with increased HR; although, interestingly, sensations of effort and thermal comfort were unaffected, despite the faster speed and higher HR.
\end{abstract}

Keywords: exercise; cooling; recovery; fatigue; thermal; environment; endurance

\section{Introduction}

Environmental stress, specifically heat stress, increases demand placed on the cardiovascular system [1,2]. Exercise also induces stress on the cardiovascular system, and the combination of heat stress with exercise can lead to a physiological challenge where demands for blood flow begin to challenge the maximal output of the heart, eventually leading to fatigue, exhaustion, and/or a decline in performance [1-7].

Accordingly, researchers have been developing strategies to prevent heat stress associated declines in exercise performance. One such approach has been the use of precooling, or reducing body temperature prior to exercise in the heat $[4,8,9]$. A review suggested that precooling via cold water immersion likely benefits performance, where ingestion of crushed ice/water ice slurry does not likely benefit performance [4]. Although the benefits of precooling, such as with cold water immersion, are not to be ignored, the issue of practicality raises concern over feasibility of implementation, and thus alternative methods ought to be explored. Strategies of attempting to cool during exercise, termed percooling, have demonstrated a positive effect on exercise performance, on par with precooling $[8,9]$, though studies of percooling are far less abundant. 
Recently, a company has developed a wearable, active cooling method (dhamaSPORT ${ }^{\text {tm }}$, DhamaUSA, Scotts Valley, CA, USA) that is light weight (115 g, $6 \mathrm{~cm}$ wide) and can be worn on the wrist during activity while posing minimal disruption or burden to the athlete (e.g., ice vest). While we have demonstrated that this wrist cooling device improved physiological recovery and reduced fatigue from an occupationally relevant model of exercise-induced heat stress [10], it has yet to be determined whether wrist percooling is capable of improving endurance performance in the heat, and if this might impact post-exercise recovery. Aside from the obvious potential to provide cooling, mitigating exercise-induced elevations in core temperature, surface percooling might activate the transient receptor potential melastatin 8 (TRPM8) "cold receptor", which might alter thermal sensation and/or exercise performance [11]. Further, recent work by Phillips et al. [7] suggests that cooling can modulate prefrontal cortex activation, perceptions of muscle fatigue or effort, and partially mitigate declines in local muscle performance. However, the impact of wrist percooling on perceptual responses during exercise in hypothermia is unknown.

Therefore, the purpose of this study was to investigate whether the wrist cooling improves exercise performance in the heat or lessen physiological strain, and if this effect is "dose-dependent." We hypothesized that wrist percooling would reduce perceptions of effort and thermal stress, reduce heart rate, and/or improve performance on a $10 \mathrm{~km}$ running time trial, and these effects would be greater with the active cooling of both wrists. Second, use of the cooling bands would improve recovery as assessed by heart rate, heart rate variability, core temperature, and reduce fatigue and thermal sensations, all of which would also be greater with the active cooling of both wrists.

\section{Materials and Methods}

\subsection{Subjects}

Fourteen exercise-trained healthy male volunteers between the ages of 18 and 54 years were recruited for this study (Figure 1). To participate in this study, all participants must have been regularly exercise training for more than one hour at least three times a week for the past four months, have a maximal oxygen consumption $\left(\mathrm{VO}_{2} \max \right)$ of $>45 \mathrm{~mL} / \mathrm{kg} / \mathrm{min}$, and $>1$ year of experience in competing in running events (e.g., $5 \mathrm{~km}, 10 \mathrm{~km}$, half-, full-, ultra-marathon, half-, full-ironman, etc.). Participants were screened, via health history, and those with cardiovascular, pulmonary, musculoskeletal, or metabolic disease, those taking regular medication, or presenting contraindications to the ingestible telemetry pill $(n=1)$ were excluded. Methodologically, women were excluded to avoid the long periods of time that would be necessary (up to 3 months) to ensure adequate recovery with parallel desire for testing to occur in a singular phase of the menstrual cycle, thus reducing the impact of hormonal fluctuations. All participants provided written informed consent prior to any testing. The protocol was approved by the Institutional Review Board of Skidmore College (IRB \# 1612-568) and was conducted in accordance with the most recent revisions to the Declaration of Helsinki.

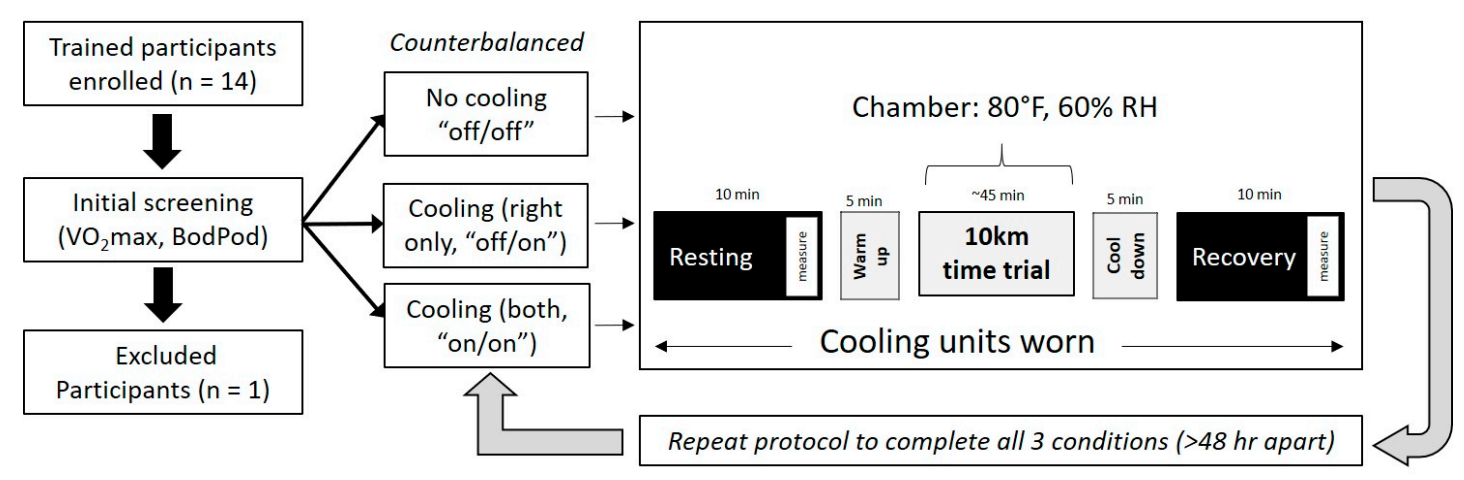

Figure 1. Experimental overview: RMR, resting metabolic rate; IET, incremental exercise test. 


\subsection{Study Overview}

The current study was conducted in a single blind, counterbalanced, crossover design to investigate the potential impact of wrist cooling on performance in, and recovery from, exercise in the heat (Figure 1). As the number of participants did not equal or equally multiply by the number of possible sequences of three trials, we used a Latin square approach to counterbalance. All testing was conducted in the Environmental Physiology Laboratory at Skidmore College. For each visit, participants were asked to avoid strenuous exercise for $24 \mathrm{~h}$ prior and alcohol/caffeine use $12 \mathrm{~h}$ prior to each study visit. Participants were instructed to maintain a similar diet and sleep regimen throughout the duration of the study. Participants were asked to wear shorts and t-shirt and to dress similarly across trials. Finally, participants were instructed to arrive each day fueled and hydrated as if preparing for a race, which included drinking the proper amount of fluids prior to each experimental visit (e.g., $~ 500 \mathrm{~mL} 2-3 \mathrm{~h}$ prior and $250 \mathrm{~mL}$ within $15 \mathrm{~min}$ of the visit). All participants reported to the laboratory on four separate occasions: a screening day and three experimental trials. While wearing two cooling bands, the three trials were conducted as follows: (1) both bands were off (off/off), (2) one band on (off/on), (3) both bands on (on/on). In the off/on condition, the right wrist was always activated. All experimental trials for a subject were completed at the same time of day to reduce impact of diurnal variation. In a thermoneutral $\left(21 \pm 1{ }^{\circ} \mathrm{C}, 29 \pm 12 \%\right.$ relative humidity) and normobaric $(\sim 750 \mathrm{mmHg})$ environment, the first screening visit assessed participant characteristics, which included anthropometrics (height, weight), body composition using air displacement plethysmography (BodPod, Cosmed, Chicago, IL, USA), and aerobic fitness via graded exercise testing on a treadmill (PPS Med, Woodway, Waukesha, WI, USA). A running protocol (modified McConnell) $[12,13]$ was used to determine maximal oxygen consumption $\left(\mathrm{VO}_{2} \mathrm{max}\right)$ using open circuit spirometry and gas analysis (TrueOne 2400, Parvomedics, Sandy, UT, USA) [14]. Prior to each experimental trial, participants were given an FDA approved core temperature telemetry pill (HQ Inc, Palmetto, FL, USA), which was taken $8-12 \mathrm{~h}$ prior to the study visit $[15,16]$.

\subsection{Procedures}

Upon arrival, a urine sample was collected and hydration status was confirmed via urine specific gravity (USG $<1.020$ ) as described previously [17]. If USG was $>1.020$, participants were given $500 \mathrm{~mL}$ of water and USG was retested thereafter (though as the participants were familiar with race preparations, this only occurred once out of 39 total visits). Participants were then instrumented with a heart rate monitor (H7, Polar USA, Lake Success, NY, USA), and the presence of the core temperature telemetry pill was confirmed (CorTemp Recorder, HQ Inc, Palmetto, FL, USA). Participants were then seated and were outfitted with two wrist cooling bands (Dhama Sport Pro, Dhama USA, Scott's Valley, USA) (Figure 2). In the "on" condition, the bands were activated and set to the coolest setting $\left(7.2{ }^{\circ} \mathrm{C}\right)$. While we attempted to avoid investigator cues and reduce possible anticipatory responses by single blinding and not making the participants' aware of which condition they were receiving, when the band was active, participants' were able to detect the cooling, but when the band was off (off/off condition) they were unsure. The device elicits cooling through a one-inch square ceramic cooling plate placed over the anterior vascular portion of the wrist, which dissipates heat via Peltier effect over a larger heat sink area on the exterior portion of the device. The heat transfer rate for this device ranges from 0.2 to 200 watts, with typical values of $0.5-50$ watts, depending upon ambient conditions. After $10 \mathrm{~min}$ of quiet rest, a one minute [18], breathing frequency paced [19], recording of heart rate (HR) and R-R intervals were obtained via HR monitor, sent to a mobile device (IPad Pro, Apple, Cupertino, CA, USA) via Bluetooth ${ }^{\mathrm{TM}}$ and analyzed by a mobile device application (Elite HRV, Gloucester, MA, USA). The Elite HRV application performs artifact correction and has been shown to be valid [20] and has been used in previous studies [10,20-22]. Specifically, along with mean HR, $\mathrm{R}-\mathrm{R}$ intervals were analyzed for the standard deviation of R-R intervals, SDNN; root mean square of successive differences, RMSSD; and the log transformed RMSSD, LnRMSSD. HRV was measured to assess potential impacts of wrist cooling on recovery as it is an increasingly recognized method to assess 
or monitor athlete acute and chronic physiological response to training, or recovery and readiness to train [22-26]. After HR and HRV were obtained, to further characterize potential impacts of wrist cooling on recovery, blood pressure (BP) was measured via oscillometric cuff method (Mobilograph, $\mathrm{GmbH}$, Stolberg, Germany) [27-29], after which thermal sensation/comfort via thermal sensation (TS) scale ( 0 "unbearably cold" to 8 "unbearably hot"), and fatigue via a visual analog scale ( 0 "no fatigue" to 10 "severe fatigue") were recorded.
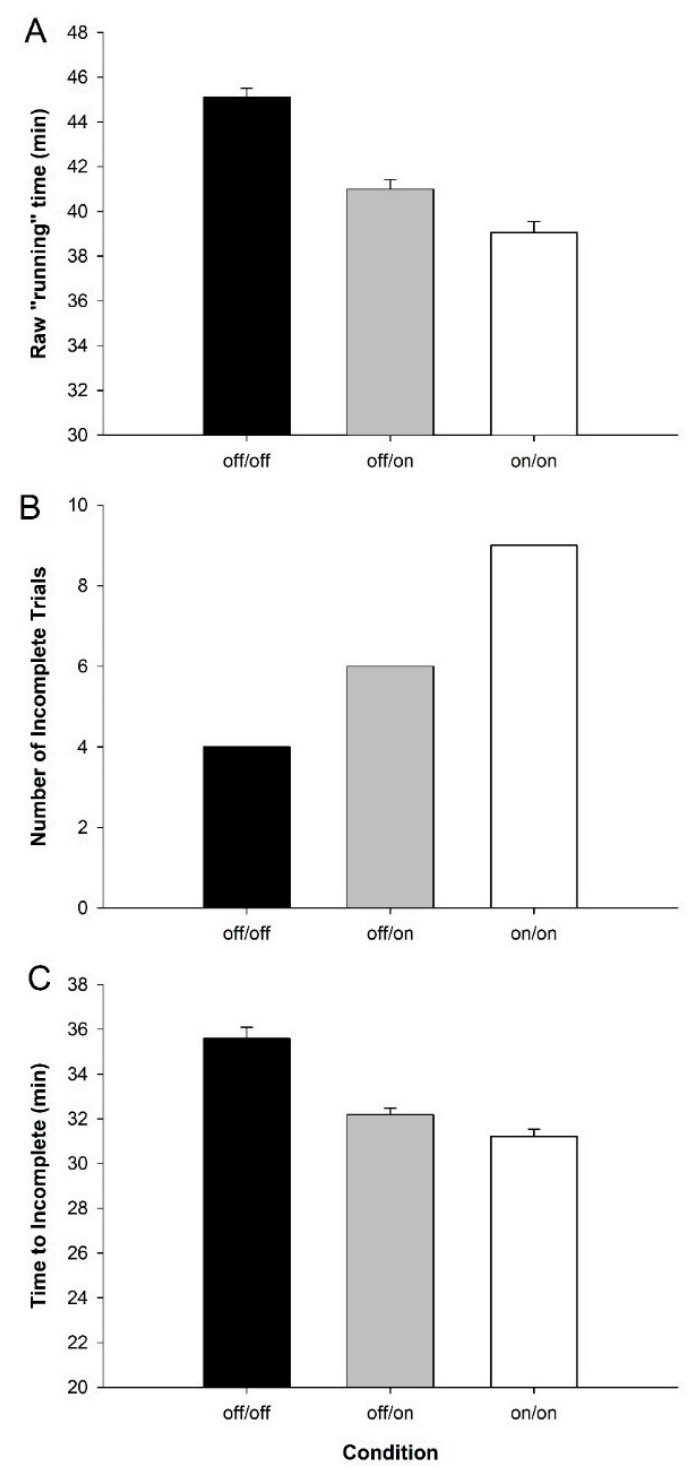

Figure 2. Raw performance data for all trials $(n=13)$ : (A) average run time, including incomplete trials across condition; (B) number of incomplete trials across condition; and (C) average time to incompletion across conditions. Data are means \pm Standard Error.

Participants were then allowed to warm up for a maximum of 5 min outside the chamber in the thermoneutral laboratory, typically followed by use of the restroom to void their bladder. Subsequently, participants entered the heated environmental chamber $\left(26.7^{\circ} \mathrm{C}, 60 \%\right.$ relative humidity, heat index of $28{ }^{\circ} \mathrm{C}$, "caution") and were instructed to complete the $10 \mathrm{~km}$ time trial ( 6.2 miles, since the treadmill was in English units) as fast as possible at $0 \%$ grade. Thus, participants were able to see their speed and allowed direct control of the treadmill speed. Verbal encouragement was provided to all participants in a consistent manner between subjects and across trials. Participants were allowed to drink water, ad libitum, during all trials, but were asked to consume fluid in a similar volume and manner across 
trials, matched for their first trial completed. During exercise, participants were asked to report their thermal sensation, rating perceived exertion using standardized visual scales every 5 min, while HR and core temperature $\left(\mathrm{T}_{\mathrm{CO}}\right)$ were monitored continuously and recorded every minute. Due to safety concerns, and institutional restrictions, in effort to avoid heat related injury, if core temperature reached two consecutive measures of $39.1{ }^{\circ} \mathrm{C}$, or a single measure of $39.2{ }^{\circ} \mathrm{C}$ or higher, the trial was ended and the participant was immediately removed from the chamber and into a cool-down period in the thermoneutral laboratory. In such case, post-measures were obtained in an identical manner as if they had completed the trial.

Once the $10 \mathrm{~km}$ trial was completed, participants were escorted from the chamber and completed a 5 min cool-down, walking on a treadmill in the thermoneutral laboratory. $\mathrm{HR}$ and $\mathrm{T}_{\mathrm{CO}}$ were continuously monitored for safety reasons. Fifteen minutes after the cessation of the exercise, a post-exercise assessment of the baseline measures, except USG, was performed, namely: VAS, thermal sensation, core temperature, HR, HRV, and BP. The timing of the post-exercise measurements was maintained for all trials, including those that were ended due to core temperature reaching our institutional safety threshold. Once post-exercise measures were obtained, the wrist cooling units were turned off and removed. Participants reported back to the laboratory to complete the other two trials in a randomized counterbalanced order as described above. Visits were completed with a minimum of $48 \mathrm{~h}$ in between (average time between visits $\sim 72 \mathrm{~h}$ ).

\subsection{Statistical Analysis}

Data were analyzed using commercially available software (SPSS v26, IBM, Armonk, NY, USA) As the number of athletes who reached our institutional safety cutoff turned out to be larger than anticipated, additional analyses were conducted to compare the number of incomplete trials between wrist percooling conditions using a chi square test, and pairwise comparisons were used to determine if the time to incompletion differed between conditions. Further, a Kaplan-Meier survival curve analysis was conducted to compare the rate and time of incompletion using a log rank test. Again, due to athletes' core temperatures reaching our institutional safety cutoff, to allow direct time-matched pairwise comparisons between trials, all trial data were analyzed to the point at which we had complete data for all participants (16 min), as well as the final data point for each participant. The final data point was either the final data at incompletion due to reaching the temperature cutoff or the final value at the end of the $10 \mathrm{~km}$ time trial. Thus, data were analyzed and plotted to the longest common time, plus each athlete's final data point, and only for one athlete in one condition were $16 \mathrm{~min}$ and final the same. Further, to estimate effects of wrist percooling on $10 \mathrm{~km}$ time trial performance, if the trial was incomplete for reaching core temperature cutoff (see Figure 2), trial performance was estimated using average running speed for the trial.

Prior to analysis, any anomalous individual data points presenting as an outlier ( $>2 \mathrm{SD})$ were removed from the data set, and where appropriate, interpolated using a linear function. Accordingly, heart rate, core temperature, and speed were analyzed using a 3 (condition) by 17 (time, $16 \mathrm{~min}+$ final) repeated measures ANOVA. For RPE and TS, a 3 (condition) by 4 (time) repeated measures ANOVA was completed. To compare the pre- and post-measurements, a 3 (condition) by 2 (time) repeated measures ANOVA was completed for HR, core temperature, RMSSD, MAP, SDNN, LnRMSSD, diastolic blood pressure (DBP), systolic blood pressure (SBP), VAS, RPE, and TS Significance was established at $p<0.05$. Data are presented as means \pm standard deviation (SD), unless indicated otherwise.

\section{Results}

\subsection{Participant Characteristics}

The participant characteristics are presented in Table 1. Most participants ( $n=10$ of 13 ) were active triathletes, having competed in half or full distance Ironman events as well as running events, 
but all had road and/or trail running racing experience. Participants were fit, with an average $\mathrm{VO}_{2}$ max of $59 \mathrm{~mL} / \mathrm{kg} / \mathrm{min}$ (range 50-71), particularly considering their average age of 33 years.

Table 1. Subject characteristics $(n=13)$.

\begin{tabular}{lc}
\hline Variable & Means \pm SD \\
\hline Age $($ years $)$ & $32.6 \pm 8.9$ \\
Height $(\mathrm{cm})$ & $178.6 \pm 9.1$ \\
Weight $(\mathrm{kg})$ & $76.9 \pm 8.0$ \\
Body Mass Index $\left(\mathrm{kg} / \mathrm{m}^{2}\right)$ & $24.1 \pm 2.1$ \\
$\mathrm{VO}_{2}$ Max $(\mathrm{mL} / \mathrm{kg} / \mathrm{min})$ & $59.1 \pm 5.2$ \\
Body Fat $\%$ & $14.8 \pm 6.8$ \\
Fat Free \% & $80.5 \pm 15.3$ \\
Body Fat Mass $(\mathrm{kg})$ & $11.5 \pm 5.4$ \\
Body Fat Free Mass $(\mathrm{kg})$ & $65.4 \pm 7.4$ \\
\hline
\end{tabular}

\subsection{Effects of Wrist Cooling on Baseline Parameters}

No significant differences were found in resting core temperature, indicators of heart rate variability, blood pressure, thermal sensation, rating of perceived exertion, or in reported fatigue using a visual analog scale between conditions (Table 2). However, use of the bands tended to affect heart rate $(p=0.05)$, where HR was elevated by $\sim 5$ beats/min in the off/on condition (Table 2$)$.

Table 2. Pre- and post-measurements for all three conditions $(n=13)$.

\begin{tabular}{ccccc}
\hline Variable & & Off/Off & Off/On & On/On \\
\hline \multirow{2}{*}{ HR (beats/min) } & Pre & $56.0 \pm 7.0$ & $61.0 \pm 8.0^{\#}$ & $59.0 \pm 6.5$ \\
& Post & $86.0 \pm 6.0$ & $87.0 \pm 6.0$ & $87.0 \pm 6.8^{*}+$ \\
\hline Core Temperature & Pre & $37.0 \pm 0.5$ & $37.2 \pm 0.6$ & $37.1 \pm 0.7$ \\
$\left({ }^{\circ} \mathrm{C}\right)$ & Post & $38.0 \pm 1.0$ & $37.3 \pm 1.6$ & $37.8 \pm 1.0$ \\
\hline \multirow{2}{*}{ MAP (mmHg) } & Pre & $106 \pm 11$ & $109 \pm 11$ & $106 \pm 10$ \\
& Post & $101 \pm 6$ & $104 \pm 8$ & $99 \pm 11^{*}$ \\
\hline \multirow{2}{*}{ SBP (mmHg) } & Pre & $124 \pm 13$ & $125 \pm 13$ & $120 \pm 12$ \\
& Post & $119 \pm 10$ & $120 \pm 9$ & $113 \pm 16$ \\
\hline \multirow{2}{*}{ DBP (mmHg) } & Pre & $85 \pm 12$ & $85 \pm 12$ & $86 \pm 10$ \\
& Post & $81 \pm 8$ & $80 \pm 10$ & $80 \pm 10^{*}$ \\
\hline \multirow{2}{*}{ LnRMSSD (a.u.) } & Pre & $4.6 \pm 0.4$ & $4.5 \pm 0.4$ & $4.56 \pm 0.5$ \\
& Post & $3.4 \pm 0.5$ & $3.5 \pm 0.7$ & $3.4 \pm 0.6^{*}$ \\
\hline \multirow{2}{*}{ SDNN (ms) } & Pre & $159.0 \pm 65.4$ & $133.8 \pm 36.3$ & $146.5 \pm 45.6$ \\
& Post & $59.6 \pm 28.2$ & $64.1 \pm 45.1$ & $64.5 \pm 29.1 *$ \\
\hline \multirow{2}{*}{ TS (0-8) } & Pre & $3.4 \pm 0.6$ & $3.2 \pm 0.4$ & $3.5 \pm 0.6$ \\
& Post & $4.6 \pm 0.9$ & $4.2 \pm 1.2$ & $4.5 \pm 0.8^{*}$ \\
\hline \multirow{2}{*}{ RPE (1-10) } & Pre & $2.0 \pm 1.0$ & $1.5 \pm 0.7$ & $2.0 \pm 0.6$ \\
& Post & $4.5 \pm 1.6$ & $5.0 \pm 2.0$ & $4.0 \pm 2.0^{*}$ \\
\hline \multirow{2}{*}{ Fatigue (VAS 1-10) } & Pre & $1.4 \pm 1.3$ & $1.7 \pm 1.1$ & $1.2 \pm 1.0$ \\
& Post & $6.2 \pm 1.8$ & $6.4 \pm 1.6$ & $5.3 \pm 2.5^{*}$ \\
\hline
\end{tabular}

$\mathrm{HR}$, heart rate; MAP, mean arterial pressure; SBP, systolic blood pressure; DBP, diastolic blood pressure; LnRMSSD, natural $\log$ transformed root mean squared of successive differences; A.U., arbitrary units; SDNN, standard deviation of normal R-R intervals; Msec, milliseconds; TS, thermal sensation; RPE, rating of perceived exertion; VAS, visual analog scale. * main effect of time; + main effect of condition, \# vs. off/off, $p<0.05$. Note: all time effects were $p<0.05$ pre vs. post. Means \pm SD. 


\subsection{Ten km Time Trial Performance}

Raw running time, including any incomplete trials, tended to decrease with the use of the bands (Figure 2A, off/on $p=0.14$ and on/on $p=0.08$ vs. off/off). However, due to participants reaching our institutionally mandated core temperature safety cut off, and importantly not of volitional means, this aforementioned time is tainted by a number of incomplete trials that tended to increase with the use of the bands (Figure 2B), and trended to an earlier incompletion time (Figure 2C). Chi squared analysis found that the proportion of incomplete trials did not significantly differ by condition $(p=0.16)$, nor were times to incompletion also not different between trials (pairwise comparisons, $p=0.51-0.81$ ). Additionally, Kaplan-Meier survival curve analysis using a log rank test revealed no significant differences in survival distribution between wrist percooling conditions ( $p=0.14$, Figure 3).

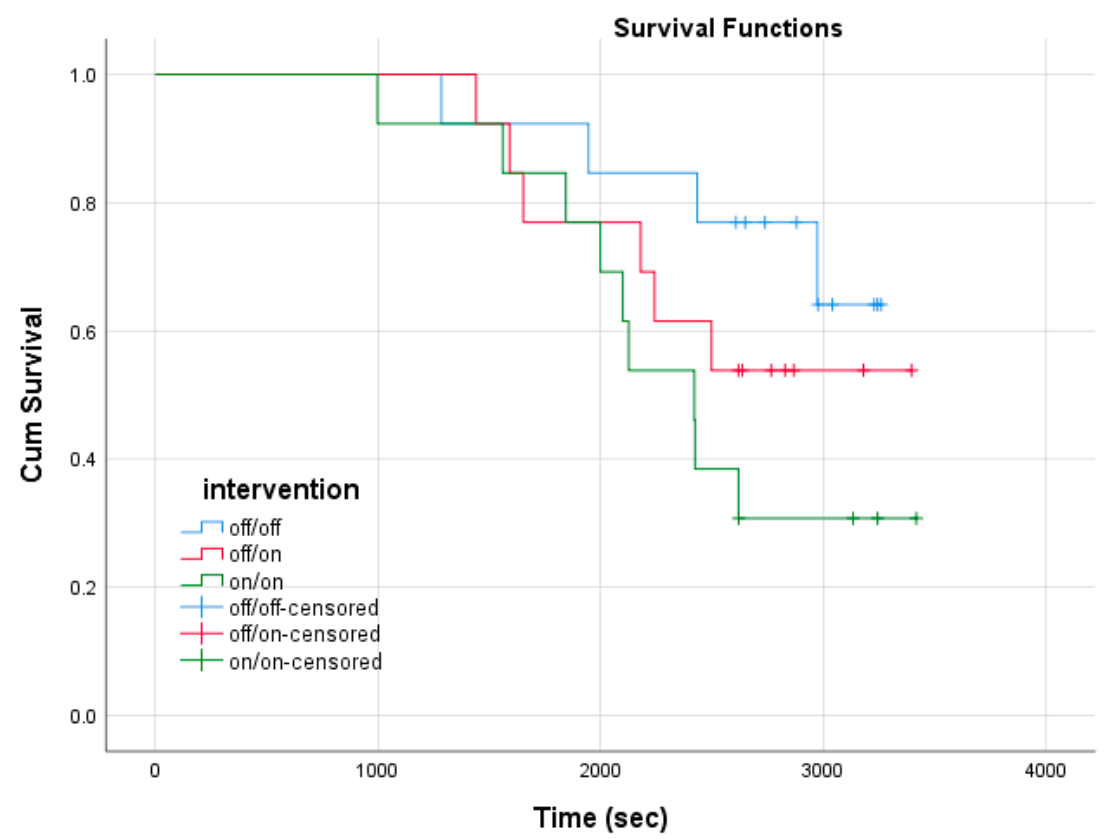

Figure 3. Kaplan-Meier survival curve across time (seconds) between wrist cooling conditions during the $10 \mathrm{~km}$ time trial.

There was a significant interaction of wrist percooling condition and time on running speed, where RS tended to increase more over time with wrist percooling (Figure 4A), though there was no main effect for condition $(p=0.13)$. Focusing on the time to which all participants had completed, the distance achieved at 16 min was not different between conditions (off/off $1.96 \pm 0.16 \mathrm{vs.} \mathrm{off/on}$ $1.98 \pm 0.19$ vs. on/on $1.99 \pm 0.24$ miles, $p=0.490$, Figure 4B). Using both actual or projected $10 \mathrm{~km}$ times, there was no statistically significant effect of the bands (off/on $p=0.49$ on/on $p=0.77$ vs. off/off), despite a tendency for an approximate $30 \mathrm{~s}$ improvement in $10 \mathrm{~km}$ time for the off/on condition and a $10 \mathrm{~s}$ improvement in $10 \mathrm{~km}$ time in the on/on condition (off/off: 50:14.6, off/on: 49:45.9, on/on: 50:04.2 min:s). Using only those with complete trials, within a condition, the trend is less clear (off/off: 49:17.4, off/on: 50:02.3, on/on: 48:51.3 min:s). 

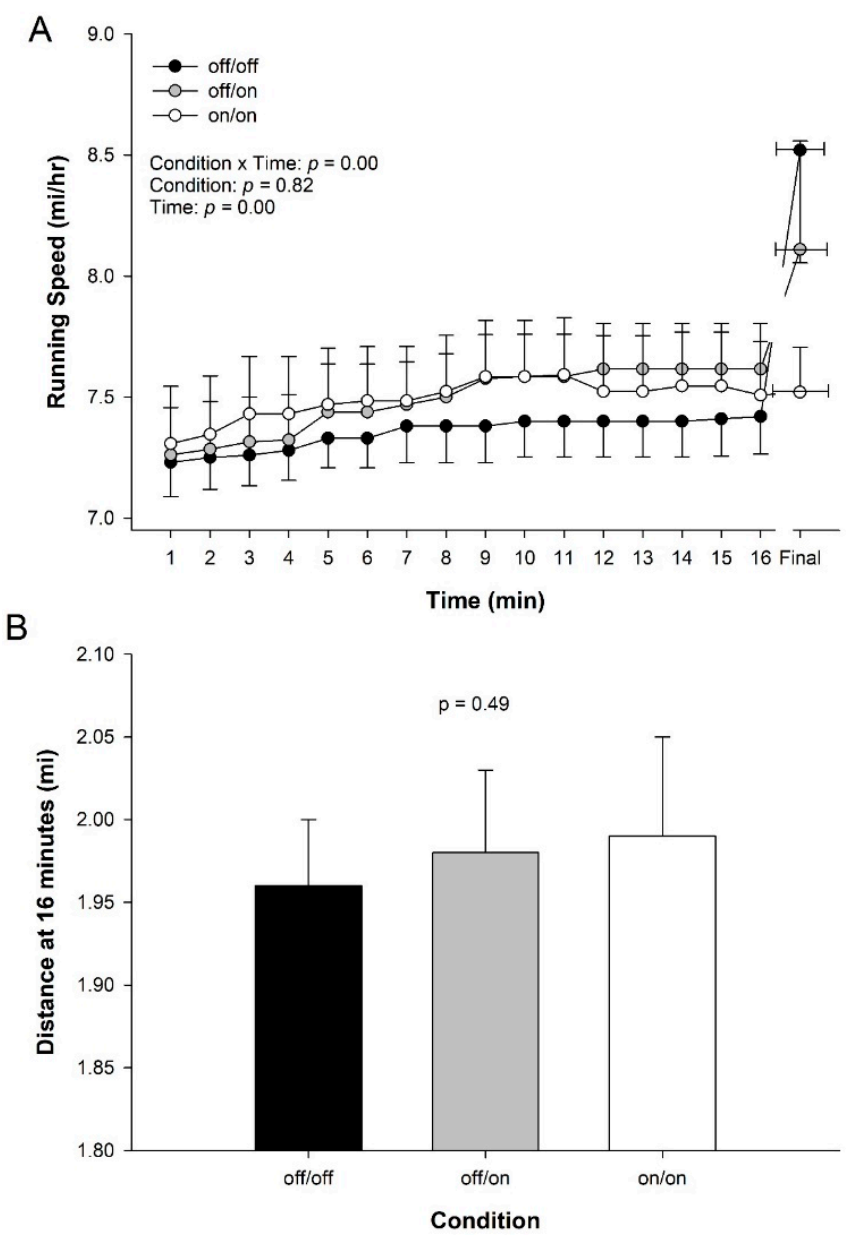

Figure 4. Running performance across wrist percooling condition. (A) Self-selected running speed during the $10 \mathrm{~km}$ time trial in the heat. Results of two-way ANOVA are presented (inset). Note: due to safety tolerance in core temperature trials were ended early and plotted to the shortest time, plus each athlete's final data point (with SE for time). (B) Distance to 16 min across wrist percooling condition $(n=13)$. This time was chosen as it was the longest point to which all participants completed at least 16 min for all 3 trials. Data are means \pm Standard Error.

\subsection{Physiological Response to $10 \mathrm{~km}$ Time Trial in the Heat}

A significant interaction between condition and time was found for heart rate ( $p=0.00$, Figure 5A). Expectedly, a main effect for time was found for heart rate throughout the trial $(p=0.00)$. No significant differences were found for heart rate between conditions $(p=0.39)$.

There was no significant interaction of condition by time for core temperature during the $10 \mathrm{~km}$ time trial (TT) ( $p=0.15$, Figure $5 \mathrm{~B})$. No main effect of condition was found during the $10 \mathrm{~km}$ time trial for core temperature $(p=0.88)$. Expectedly, however, there was a significant effect of time on core temperature during the trial ( $p<0.001$, Figure 5B).

\subsection{Perceptual Measures during $10 \mathrm{Km}$ Time Trial in the Heat}

There was no significant interaction between condition and time for thermal sensation during the $10 \mathrm{~km}(p=0.96$, Figure 6A). A significant main effect was found for time, where the participants' TS increased over time $(p=0.00)$, though no significant differences were observed between conditions for TS $(p=0.47)$. 

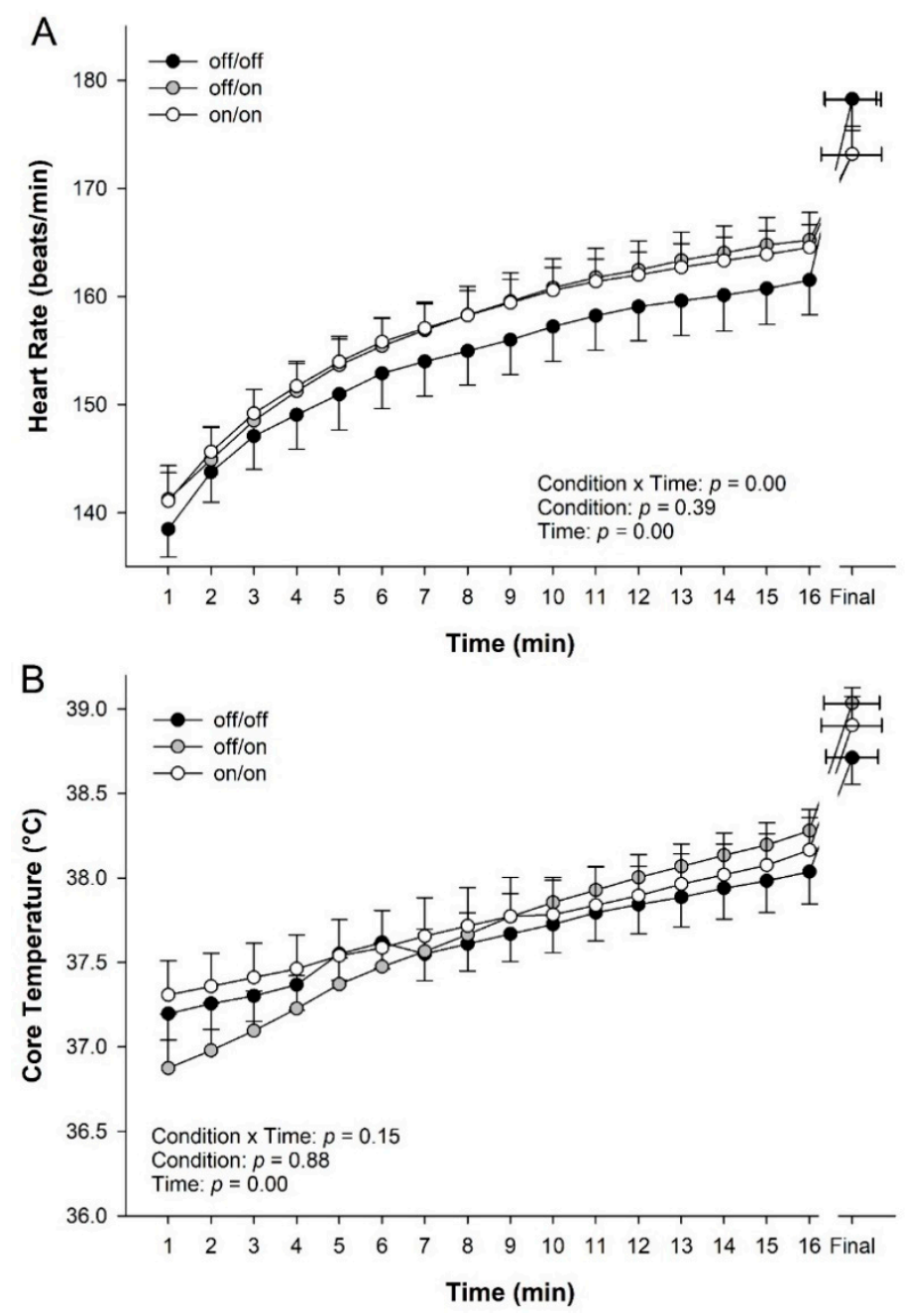

Figure 5. Physiological responses to $10 \mathrm{~km}$ time trial in the heat across wrist percooling condition. (A) Heart rate and (B) core temperature during $10 \mathrm{~km}$ time trial. Note: due to safety tolerance in core temperature, trials were ended early and plotted to the shortest time, plus each athlete's final data point. Data are means \pm Standard Error $(n=13)$.

No significant interaction of condition and time was found for RPE ( $p=0.38$, Figure $6 \mathrm{~B})$. Naturally, a main effect for time was found $(p=0.000)$. However, RPE did not significantly differ between conditions $(p=0.93)$.

\subsection{Impact of Wrist Cooling on Recovery}

Pre- and post-measurements are shown in Table 2. No significant interaction $(p=0.58)$ was found between condition and time for core temperature, though core temperature was on average 0.2 to $0.7^{\circ} \mathrm{C}$ cooler in recovery with use of the bands. Although core temperature approached significance, there was not a significant effect of time $(p=0.05)$; core temperature was not different from baseline and had recovered. However, there was no effect of condition on core temperature $(p=0.64)$.

There was no significant interaction between condition and time for heart rate $(p=0.36$, Table 2$)$. There was a significant main effect for time $(p=0.00)$ on heart rate with elevations post-exercise. Heart rate significantly differed between conditions, where heart rate tended to increase with the use of the bands (condition effect $p=0.03$ ). To measure heart rate variability, the root mean square of the successive differences (RMSSD) was measured. No significant interaction effect for condition by time $(p=0.23)$ and no main effect of condition was found $(p=0.97)$. A significant main time effect was found for RMSSD ( $p=0.000$, Table 2 ) with a significantly reduced RMSSD post-exercise. In addition, 
there was no significant interaction effect for condition by time $(p=0.43)$ and no difference between conditions ( $p=0.96$ ) for log transformed RMSSD (LnRMSSD). Expectedly, similar to RMSSD, there was a main time effect for LnRMSSD ( $p=0.00$, Table 2$)$ with lower HR variability post-exercise. Lastly, SDNN had no significant condition effect $(p=0.41)$ or condition by time effect $(p=0.15)$. Corresponding to the other heart rate variability variables, there was a main time effect for SDNN $(p=0.00)$ with lower HR variability post-exercise.

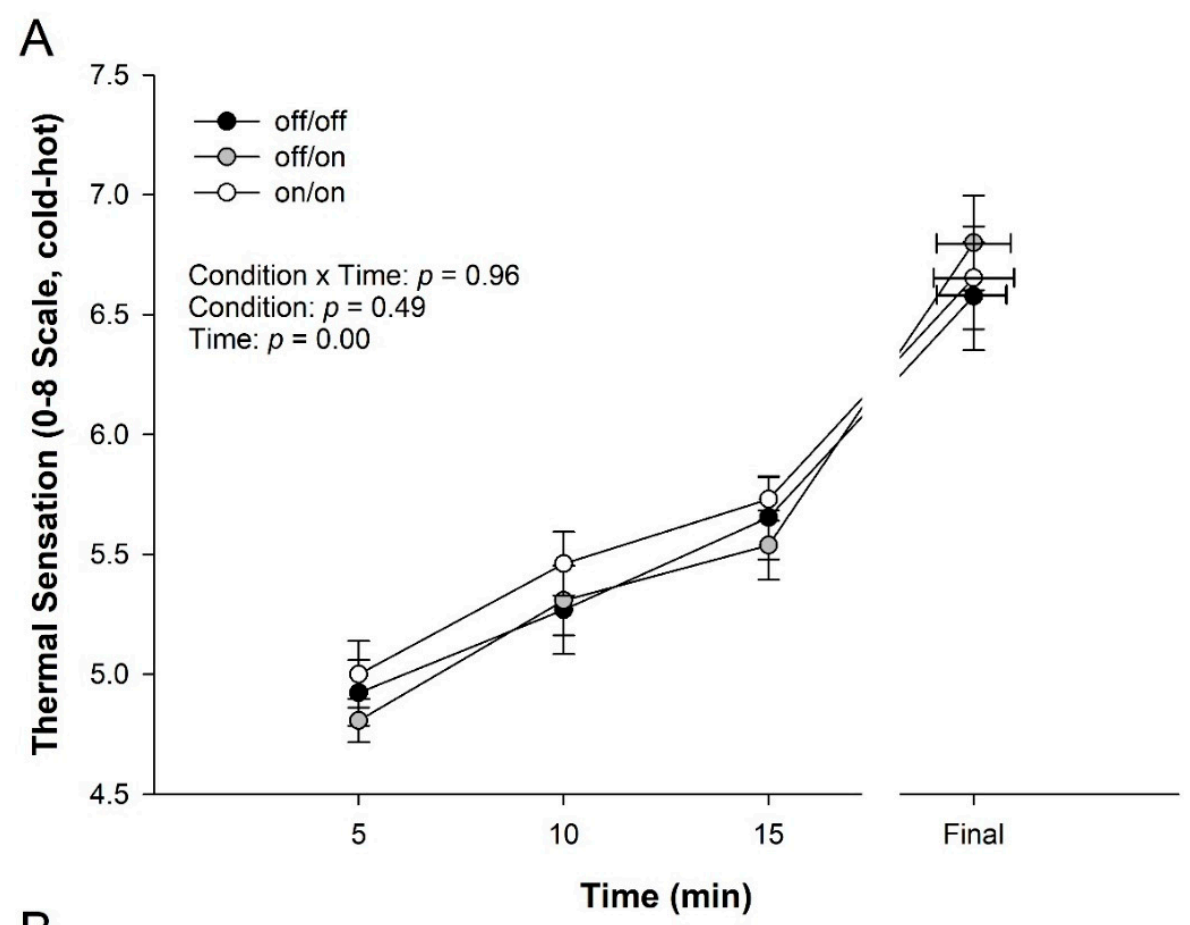

B

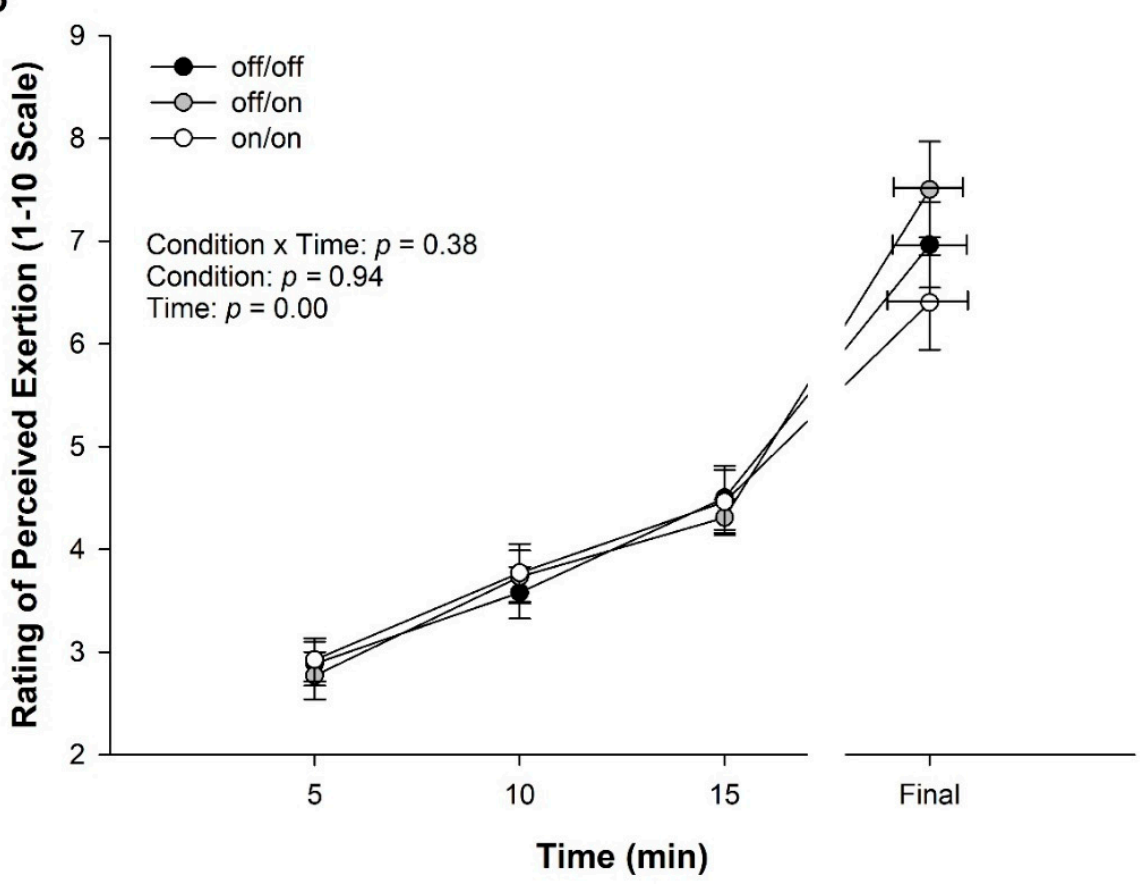

Figure 6. Perceptual measures during $10 \mathrm{~km}$ TT. (A) Thermal sensation (TS) and (B) Rating of perceived exertion. Note: due to safety tolerance in core temperature, trials were ended early and plotted to the shortest time, plus each athlete's final data point. Data are means \pm Standard Error, $(n=13)$. 
No significant interaction for condition by time was found for mean arterial pressure, MAP $(p=0.90$, Table 2$)$. During the recovery process, a main effect of time was found for MAP $(p=0.01)$ with lower MAP in recovery, though no significant differences between conditions were found $(p=0.08)$. Systolic blood pressure, SBP, showed no significance for main time effect, condition by time, or condition (all $p>0.05$, Table 2). Diastolic blood pressure, DBP, had no significant interaction of condition by time $(p=0.28)$ or effect of condition $(p=0.11)$. In contrast to SBP, DBP had a significant main time effect $(p=0.02)$ with a reduction in diastolic pressure post-exercise.

During recovery, there was no significant interaction between condition and time for RPE $(p=0.08)$ and TS ( $p=0.72)$. There was a significant main effect of time for RPE and TS (both $p=0.000$, Table 2). No significant differences between conditions were present for RPE $(p=0.43)$ and TS $(p=0.33)$. There was no significant interaction between condition and time for the fatigue visual analog scale $(p=0.47$, Table 2). Expectedly, a main effect of time was present during the recovery process for VAS $(p=0.00)$, showing higher reported levels of fatigue, but no significant difference was found between conditions in the recovery process $(p=0.10)$.

\section{Discussion}

The intent of this study was to ascertain whether percooling via wrist cooling bands would improve $10 \mathrm{~km}$ running time trial performance in the heat, or lessen the physiological strain, and enhance recovery. The main finding of this study was that the use of the bands seemed to promote the participants to run at a faster speed over time. Thus, when using the bands, there was a corresponding increase in heart rate over time as a result of this increased speed and energy demand. On average, core temperature, thermal sensation, and rating of perceived exertion were not different when using the bands. Use of the bands did not appear to alter baseline or enhance physiological or perceptual indicators of recovery from the $10 \mathrm{~km}$ running bout. There was also no clear evidence that two bands were more advantageous than one, in terms of the physiological and perceptual responses to exercise, performance, or recovery. Thus, athletes considering use of wrist percooling, wearing one band is likely sufficient and possibly optimal. In conclusion, the cooling bands elicited a faster running speed over time; however, this comes at a physiological cost, but surprisingly not a perceptual one. Further work in the field or in unrestricted settings are needed to ultimately demonstrate efficacy of wrist percooling.

\subsection{Ten km Time Trial Performance}

In the present study, we observed that wrist percooling through the use of wrist cooling bands seemed to elicit a faster running speed in the participants over time (interaction effect, Figure 4). The faster self-selected running speed over time could be interpreted as an increase in performance because, all else held constant, would be expected to lead to a faster $10 \mathrm{~km}$ time trial. Focusing on distance covered at a common time, the distance covered by the athletes was not statistically higher at $16 \mathrm{~min}$, a critical time point in our study. Using completed and estimated $10 \mathrm{~km}$ times, wrist percooling via use of the band's lead to times that were on average $\sim 20 \mathrm{~s}$ faster, but were not significantly different from control. The faster running speed, as an indicator of performance, agrees with prior research using precooling, which also observed an increase in performance [9,30-34].

Previous reviews indicated that the magnitude of the effect of precooling likely depends upon the modality of precooling (e.g., water immersion, and depth, ice slurry, cooling garment, etc.) and how performance is assessed (i.e., time to exhaustion, and prescribed intensity, time trial, distance trial, etc.) $[4,9]$. Specifically, cold water immersion elicits an effect size (Cohens d) of 0.4 to 2 on performance vs. control, whereas precooling garments elicit an effect size of 0.1 to 0.5 (small to medium) [4], the latter more reflecting the magnitude effect in the current study (Cohens d effect size of 0.2 , small effect, in off/off vs. off/on). Although the trend for a positive effect on actual or estimated $10 \mathrm{~km}$ time was not statistically significant, it should not be interpreted necessarily as useless. A 10-30 s effect on $10 \mathrm{~km}$ performance could have practical implications. To put this modest effect into perspective, when looking at the professional men's results of the 2016 AJC Peachtree road race, one of the nation's largest 
$10 \mathrm{~km}$ events, run in Atlanta, GA, during July (similar environmental conditions at race start to those in our study), a $20 \mathrm{~s}$ boost in performance could mean being on the podium or not. For the Bolder Boulder $10 \mathrm{~km}$ race, one of the largest $10 \mathrm{~km}$ races in the world, first place through sixth place in the pro division was separated by $20 \mathrm{~s}$. Again, further field testing is needed to support this notion, though as climatic temperatures rise and running events are held in hot environments (e.g., Tokyo 2021 Olympic games), developing viable methods of supporting athlete's performance is increasingly paramount.

\subsection{Impact of Wrist Percooling on Physiological Responses to $10 \mathrm{~km}$ TT in the Heat}

In the current study, core temperature during the $10 \mathrm{~km}$ time trial was unaffected by percooling via wrist cooling bands (Figure 5). The present findings are in contrast to previous work using precooling, which demonstrated reduced core temperature particularly during initial stages of exercise $[31,32,35,36]$. For example, in a study by Lee and Haymes [32], $30 \mathrm{~min}$ of precooling reduced core temperature at rest and during exercise, though final core temperatures were not different between precooled and control. In agreement, when using a mix-method of ice bags and a cooling vest, Duffield et al. [31] saw a decrease in core temperature during warm up and the first sprinting periods; however, there was no significant difference in the final core temperature. Precooling is thought to reduce core temperature, creating a larger reservoir or tolerance for core temperature increases, postponing increases in temperature to the latter stage of exercise. In the current study, it was hypothesized that the use of the bands would blunt the rise of core temperature and lower it during the $10 \mathrm{~km}$ time trial, but this was not observed. However, given the running speed was increased over time, further challenging the cooling capacity of the unit due to the additional metabolic heat load, in already loaded condition, observing such an effect may not be possible. The cooling power of the device, maximally 200 watts, is simply not capable of ablating human heat production, estimated at over 1000 watts [37], but whether it might attenuate the rise in core temperature in individuals warrants further study.

Concordant to the increased running speed over time seen with wrist percooling, heart rate also was elevated over time during the $10 \mathrm{~km}$ time trial (Figure 5). These results somewhat support one previous study done by Duffield et al. [31], where they found no significant difference in heart rate during the exercise. However, previous research found with various models of precooling that HR was suppressed $[30,32,33,35,38]$, at least during the initial stages of exercise, as final HR often was not different between conditions. However, some of these protocols used steady state exercise models [35], others incremental [33,38], or time to exhaustion [30,32], where speed or work load were matched. Thus, the higher heart rate over the trial with the use of the bands, while perhaps in disagreement with previous studies and not supporting the hypothesis, makes physiological sense in the context of the increased running speed.

\subsection{Impact of Wrist Percooling on Perceptual Measures during $10 \mathrm{~km}$ TT in the Heat}

The current study found no significant difference between conditions and no interaction effect for RPE (Figure 6). In support of the present data, Duffield et al. [31,36] also found no significant difference between the precooling and control conditions for RPE during the performance trial. However, other studies showed that RPE decreased with the use of precooling methods during the exercise performance $[35,39]$. However, in both of these studies walking/running speed was fixed.

Similar to RPE, in the present study, thermal sensation or perception during the $10 \mathrm{~km}$ time trial was not different between conditions and did not see an interaction effect with the use of the bands (Figure 6). Only one previous study supports the present data that showed no significant difference between conditions during the performance [31]. Other research has proven that with the use of cooling, the TS decreases during exercise [35,39,40].

Thus, while the present data does not support the hypothesis that the use of the cooling bands would have lowered RPE and TS, the present data are to be considered in the context of altered running speed over time. Recent meta-analysis suggests that topical or ingestion of menthol, a known agonist of the "cold receptor," TRPM8, can alter thermal sensation and/or exercise performance [11], perhaps 
independent of core temperature [41]. Relatedly, work by Phillips et al. [7] suggests that precooling might modulate the prefrontal cortex and/or its processing of afferent feedback regarding perceptions of effort, fatigue, or skin temperature, which might support greater exercise tolerance, and ultimately an attenuation of muscle fatigue. Thus, while it is tempting to speculate that RPE and TS might have been expected to increase in response to the increased running speed, and that the cooling bands mitigated the expected increase in perception of effort and thermal strain, further work is needed to confirm this hypothesis and explore the potential psychophysiological effects of wrist percooling.

\subsection{Impact of Wrist Percooling on Physiological Recovery}

In contrast to our initial hypothesis, core temperature did not significantly differ between conditions during recovery (Table 2). A prior meta-analytical review demonstrated that more aggressive cooling methods, such as whole body cooling likely help to recover performance [42], though few studies have focused on recovery of core temperature. Much of this work has been done in occupational models, such as firefighting, using multiple interventions, some invasive, to induce cooling and recovery of heart rate after firefighting [43-47]. Accordingly, our previous work using this wrist cooling device to induce cooling after an occupational model of exercise-induced heat stress via exercise in encapsulating clothing, revealed a significant positive impact of wrist cooling on recovery of temperature and heart rate [10]. However, in that study the exercise was necessarily more modest (walking) and shorter, thus the rise in core temperature was lower, all only increasing by $1{ }^{\circ} \mathrm{C}$ or less, potentially creating multiple differentials between the present and the aforementioned study. Interestingly, heart rate was found to be significantly impacted by wrist cooling at rest, and agrees with previous work that demonstrated skin cooling to $7^{\circ} \mathrm{C}$ resulted in a modest 5 beat $/$ min increase, likely the result of activating sensory afferent neurons [48]. This resting difference, we believe, contributed to a main effect of condition when exploring rest and recovery, as post-exercise HR values were not actually different between conditions. In support of no difference in heart rate during recovery between conditions, Edmonds et al. [40] using the wrist cooling device also found no significant difference in heart rate after high intensity physical activity. Thus, wrist cooling may be insufficient to hasten recovery of HR after high intensity activity in the heat.

\subsection{Impact of Wrist Percooling on Recovery of Perceptual Measurements}

During the recovery period, there was no significant difference in TS. However, TS during the recovery period was recorded highest in the off/off condition (4.6) and the lowest in the on/on condition (4.2). In support of this, Edmonds et al. [40] found a significant decrease during the recovery period, at the 10 min marker. The present data do show a lower value with the use of the bands; however, due to the time to incompletion decreasing with the bands, and the number of incomplete trials increasing, perceptual cues could be altered due to the decrease in performance. In recovery, RPE, or perhaps more appropriately the fatigue visual analog scale values after the exercise did not significantly differ, which does disagree with our prior work [10] using wrist cooling. Although for the reasons mentioned above, this may be expected. Future studies should explore the potential impact of wrist cooling on recovery in the field or athletic setting where immediate cooling applications may not be readily available and thus wrist cooling could perhaps be a bridge from or to more powerful cooling methods, such as cold-water immersion.

\subsection{Experimental Considerations}

The $10 \mathrm{~km}$ time trial took place in a controlled environment during the winter months and therefore the athletes were not acclimated to running in hot and humid environments. Institutional safety mandated cessation of exercise just above $39^{\circ} \mathrm{C}$ (Figure 2), impairing our ability to determine whether performance would have truly been affected; indeed, previous work has suggested that high-level athletes are capable of tolerating such core temperatures or higher, perhaps even to $41.5^{\circ} \mathrm{C}$ [49]. Anecdotally, none of the participants exhibited any heat-related illness signs or symptoms, suggestive 
of a greater tolerance, and this may have underestimated potential performance effects as the athletes were unable to fully execute their individual race plan (e.g., negative splits or sprint at the end). Nonetheless due to this cutoff, in trials where the athlete reached this threshold we estimated or projected their performance. Future studies are needed to determine possible effects in a relatively unrestricted or field environment to observe fully the potential effects on performance. Although ingestible temperature telemetry pills have been demonstrated valid and able to track changes over time with heating or cooling $[15,16]$, there was some variability in core temperature measurements with the telemetry pill and future studies might consider using more invasive measures such as esophageal or rectal thermistors. It was impossible to conduct the study in a fully blinded or placebo-controlled manner, though the research team sought to minimize eliciting any anticipatory responses, and participants wore both bands during all three trials. Measures of skin temperatures and/or localized thermal sensations would have enhanced the study, and future studies using this cooling method should include these measures, as well as pulmonary measures (e.g., $\mathrm{VO}_{2}$, ventilation, respiratory exchange ratio).

\section{Conclusions}

In the present study, wrist percooling during a $10 \mathrm{~km}$ TT in the heat resulted in a faster self-selected running speed and higher heart rates, though thermal sensation or perceptions of effort were unaffected. The increased running speed over time with wrist percooling might be practically meaningful, but further work is needed to determine the potential impacts of wrist cooling on performance, particularly in the field.

Author Contributions: Conceptualization, S.J.I.; methodology, K.D., R.C., E.S. and S.J.I.; formal analysis, K.D., R.C., E.S. and S.J.I.; investigation, K.D., R.C., E.S. and S.J.I.; resources, S.J.I.; data curation, K.D., R.C., E.S. and S.J.I.; writing - original draft preparation, K.D. and S.J.I.; writing-review and editing, K.D., R.C., E.S. and S.J.I.; visualization, K.D. and S.J.I.; supervision, S.J.I.; project administration, S.J.I.; funding acquisition, S.J.I. All authors have read and agreed to the published version of the manuscript.

Funding: This research was supported, in part, by DhamaUSA.

Acknowledgments: The authors would like to thank the Empire Endurance triathlon team and those who graciously volunteered for the study. We would also like to thank Michael Lopez in the Department of Mathematics and Statistics at Skidmore for his assistance. We would like to thank DhamaUSA for providing cooling units and financial support.

Conflicts of Interest: The funders had no role in the design of the study; in the collection, analyses, or interpretation of data; in the writing of the manuscript, or in the decision to publish the results.

\section{References}

1. Crandall, C.G.; Gonzalez-Alonso, J. Cardiovascular function in the heat-stressed human. Acta Physiol. 2010, 199, 407-423. [CrossRef] [PubMed]

2. Rowell, L.B. Human cardiovascular adjustments to exercise and thermal stress. Physiol. Rev. 1974, 54, 75-159. [CrossRef] [PubMed]

3. Van Haitsma, T.A.; Light, A.R.; Light, K.C.; Hughen, R.W.; Yenchik, S.; White, A.T. Fatigue sensation and gene expression in trained cyclists following a $40 \mathrm{~km}$ time trial in the heat. Eur. J. Appl. Physiol. 2016, 116, 541-552. [CrossRef] [PubMed]

4. Jones, P.R.; Barton, C.; Morrissey, D.; Maffulli, N.; Hemmings, S. Pre-cooling for endurance exercise performance in the heat: A systematic review. BMC Med. 2012, 10, 166. [CrossRef] [PubMed]

5. Tatterson, A.J.; Hahn, A.G.; Martin, D.T.; Febbraio, M.A. Effects of heat stress on physiological responses and exercise performance in elite cyclists. J. Sci. Med. Sport 2000, 3, 186-193. [CrossRef]

6. Ely, B.R.; Cheuvront, S.N.; Kenefick, R.W.; Sawka, M.N. Aerobic performance is degraded, despite modest hyperthermia, in hot environments. Med. Sci. Sports Exerc. 2010, 42, 135-141. [CrossRef] [PubMed]

7. Phillips, K.C.; Verbrigghe, D.; Gabe, A.; Jauquet, B.; Eischer, C.; Yoon, T. The influence of thermal alterations on prefrontal cortex activation and neuromuscular function during a fatiguing task. Int. J. Environ. Res. Public Health 2020, 17, 7194. [CrossRef] [PubMed] 
8. Bongers, C.C.; Thijssen, D.H.; Veltmeijer, M.T.; Hopman, M.T.; Eijsvogels, T.M. Precooling and percooling (cooling during exercise) both improve performance in the heat: A meta-analytical review. Br. J. Sports Med. 2015, 49, 377-384. [CrossRef]

9. Tyler, C.J.; Sunderland, C.; Cheung, S.S. The effect of cooling prior to and during exercise on exercise performance and capacity in the heat: A meta-analysis. Br. J. Sports Med. 2015, 49, 7-13. [CrossRef]

10. Schlicht, E.; Caruso, R.; Denby, K.; Matias, A.; Dudar, M.; Ives, S.J. Effects of wrist cooling on recovery from exercise-induced heat stress with firefighting personal protective equipment. J. Occup. Environ. Med. 2018, 60, 1049-00. [CrossRef]

11. Jeffries, O.; Waldron, M. The effects of menthol on exercise performance and thermal sensation: A meta-analysis. J. Sci. Med. Sport 2019, 22, 707-715. [CrossRef] [PubMed]

12. McConnell, T.R.; Clark, B.A. Treadmill protocols for determination of maximum oxygen uptake in runners. Br. J. Sports Med. 1988, 22, 3-5. [CrossRef] [PubMed]

13. Ives, S.J.; Blegen, M.; Coughlin, M.A.; Redmond, J.; Matthews, T.; Paolone, V. Salivary estradiol, interleukin-6 production, and the relationship to substrate metabolism during exercise in females. Eur. J. Appl. Physiol. 2011, 111, 1649-1658. [CrossRef]

14. Crouter, S.E.; Antczak, A.; Hudak, J.R.; DellaValle, D.M.; Haas, J.D. Accuracy and reliability of the parvomedics trueone 2400 and medgraphics vo2000 metabolic systems. Eur. J. Appl. Physiol. 2006, 98, 139-151. [CrossRef]

15. Byrne, C.; Lim, C.L. The ingestible telemetric body core temperature sensor: A review of validity and exercise applications. Br. J. Sports Med. 2007, 41, 126-133. [CrossRef] [PubMed]

16. O’Brien, C.; Hoyt, R.W.; Buller, M.J.; Castellani, J.W.; Young, A.J. Telemetry pill measurement of core temperature in humans during active heating and cooling. Med. Sci. Sports Exerc. 1998, 30, 468-472. [CrossRef]

17. Matias, A.; Dudar, M.; Kauzlaric, J.; Frederick, K.A.; Fitzpatrick, S.; Ives, S.J. Rehydrating efficacy of maple water after exercise-induced dehydration. J. Int. Soc. Sports Nutr. 2019, 16, 5. [CrossRef]

18. Esco, M.R.; Flatt, A.A. Ultra-short-term heart rate variability indexes at rest and post-exercise in athletes: Evaluating the agreement with accepted recommendations. J. Sports Sci. Med. 2014, 13, 535-541.

19. Aysin, B.; Aysin, E. Effect of respiration in heart rate variability (hrv) analysis. In Proceedings of the 2006 International Conference of the IEEE Engineering in Medicine and Biology Society, New York, NY, USA, 30 August-3 September 2006; pp. 1776-1779.

20. Perrotta, A.S.; Jeklin, A.T.; Hives, B.A.; Meanwell, L.E.; Warburton, D.E.R. Validity of the elite hrv smartphone application for examining heart rate variability in a field-based setting. J. Strength Cond. Res. 2017, 31, 2296-2302. [CrossRef]

21. Flatt, A.A.; Esco, M.R. Smartphone-derived heart-rate variability and training load in a women's soccer team. Int. J. Sports Physiol. Perform. 2015, 10, 994-1000. [CrossRef]

22. Flatt, A.A.; Esco, M.R. Evaluating individual training adaptation with smartphone-derived heart rate variability in a collegiate female soccer team. J. Strength Cond. Res. Natl. Strength Cond. Assoc. 2016, 30, 378-385. [CrossRef]

23. Edmonds, R.; Burkett, B.; Leicht, A.; McKean, M. Effect of chronic training on heart rate variability, salivary iga and salivary alpha-amylase in elite swimmers with a disability. PLoS ONE 2015, 10, e0127749. [CrossRef]

24. Egan-Shuttler, J.D.; Edmonds, R.; Ives, S.J. The efficacy of heart rate variability in tracking travel and training stress in youth female rowers: A preliminary study. J. Strength Cond. Res. Natl. Strength Cond. Assoc. 2018. [CrossRef]

25. Flatt, A.A.; Esco, M.R.; Nakamura, F.Y. Individual heart rate variability responses to preseason training in high level female soccer players. J. Strength Cond. Res. Natl. Strength Cond. Assoc. 2017, 31, 531-538. [CrossRef]

26. Plews, D.J.; Laursen, P.B.; Stanley, J.; Kilding, A.E.; Buchheit, M. Training adaptation and heart rate variability in elite endurance athletes: Opening the door to effective monitoring. Sports Med. 2013, 43, 773-781. [CrossRef] [PubMed]

27. Izzo, J.; Saleem, O.; Khan, S.; Osmond, P. 7b.05: Differential effects nebivolol and valsartan alone and in combination on 24-h ambulatory rate-pressure product, stroke load, and blood pressure-heart rate variability. J. Hypertens. 2015, 33 (Suppl. 1), e93. [CrossRef] 
28. Izzo, J.L., Jr.; Khan, S.U.; Saleem, O.; Osmond, P.J. Ambulatory 24-hour cardiac oxygen consumption and blood pressure-heart rate variability: Effects of nebivolol and valsartan alone and in combination. J. Am. Soc. Hypertens. JASH 2015, 9, 526-535. [CrossRef]

29. Varrenti, M.; Meani, P.; Giupponi, L.; Vallerio, P.; Ferrari, E.; Stucchi, M.; Maloberti, A.; Bruno, J.; Turazza, F.; Parati, G.; et al. 1b.01: $24 \mathrm{~h}$ modulation of peripheral and central blood pressure, heart rate and arterial stiffness in heart transplant hypertensive individuals. J. Hypertens. 2015, 33 (Suppl. 1), e5. [CrossRef]

30. Booth, J.; Marino, F.; Ward, J.J. Improved running performance in hot humid conditions following whole body precooling. Med. Sci. Sports Exerc. 1997, 29, 943-949. [CrossRef] [PubMed]

31. Duffield, R.; Steinbacher, G.; Fairchild, T.J. The use of mixed-method, part-body pre-cooling procedures for team-sport athletes training in the heat. J. Strength Cond. Res. Natl. Strength Cond. Assoc. 2009, 23, 2524-2532. [CrossRef]

32. Lee, D.T.; Haymes, E.M. Exercise duration and thermoregulatory responses after whole body precooling. J. Appl. Physiol. (Bethesda Md. 1985) 1995, 79, 1971-1976. [CrossRef] [PubMed]

33. Uckert, S.; Joch, W. Effects of warm-up and precooling on endurance performance in the heat. Br. J. Sports Med. 2007, 41, 380-384. [CrossRef] [PubMed]

34. Yeargin, S. Precooling improves endurance performance in the heat. Clin. J. Sport Med. 2008, 18, 177-178. [PubMed]

35. Kenny, G.P.; Schissler, A.R.; Stapleton, J.; Piamonte, M.; Binder, K.; Lynn, A.; Lan, C.Q.; Hardcastle, S.G. Ice cooling vest on tolerance for exercise under uncompensable heat stress. J. Occup. Environ. Hyg. 2011, 8, 484-491. [CrossRef]

36. Duffield, R.; Green, R.; Castle, P.; Maxwell, N. Precooling can prevent the reduction of self-paced exercise intensity in the heat. Med. Sci. Sports Exerc. 2010, 42, 577-584. [CrossRef]

37. Gleeson, M. Temperature regulation during exercise. Int. J. Sports Med. 1998, 19 (Suppl. 2), S96-S99. [CrossRef]

38. Smith, D.L.; Fehling, P.C.; Hultquist, E.M.; Arena, L.; Lefferts, W.K.; Haller, J.M.; Storer, T.W.; Cooper, C.B. The effect of precooling on cardiovascular and metabolic strain during incremental exercise. Appl. Physiol. Nutr. Metab. Physiol. Appl. Nutr. Metab. 2013, 38, 935-940. [CrossRef]

39. Siegel, R.; Mate, J.; Brearley, M.B.; Watson, G.; Nosaka, K.; Laursen, P.B. Ice slurry ingestion increases core temperature capacity and running time in the heat. Med. Sci. Sports Exerc. 2010, 42, 717-725. [CrossRef]

40. Edmonds, R.C.; Wilkinson, A.F.; Fehling, P.C. Novel cooling device enhances autonomic nervous system recovery from live fire training: A pilot study. Int. J. Innov. Res. Med Sci. 2017, 2, 455-460. [CrossRef]

41. Hue, O.; Chabert, C.; Collado, A.; Hermand, E. Menthol as an adjuvant to help athletes cope with a tropical climate: Tracks from heat experiments with special focus on guadeloupe investigations. Front. Physiol. 2019, 10, 1360. [CrossRef]

42. Poppendieck, W.; Faude, O.; Wegmann, M.; Meyer, T. Cooling and performance recovery of trained athletes: A meta-analytical review. Int. J. Sports Physiol. Perform. 2013, 8, 227-242. [CrossRef] [PubMed]

43. Colburn, D.; Suyama, J.; Reis, S.E.; Morley, J.L.; Goss, F.L.; Chen, Y.-F.; Moore, C.G.; Hostler, D. A comparison of cooling techniques in firefighters after a live burn evolution. Prehospital Emerg. Care 2011, 15, $226-232$. [CrossRef] [PubMed]

44. Hostler, D.; Reis, S.E.; Bednez, J.C.; Kerin, S.; Suyama, J. Comparison of active cooling devices with passive cooling for rehabilitation of firefighters performing exercise in thermal protective clothing: A report from the fireground rehab evaluation (fire) trial. Prehospital Emerg. Care 2010, 14, 300-309. [CrossRef]

45. Barr, D.; Reilly, T.; Gregson, W. The impact of different cooling modalities on the physiological responses in firefighters during strenuous work performed in high environmental temperatures. Eur. J. Appl. Physiol. 2011, 111, 959-967. [CrossRef] [PubMed]

46. McEntire, S.J.; Suyama, J.; Hostler, D. Mitigation and prevention of exertional heat stress in firefighters: A review of cooling strategies for structural firefighting and hazardous materials responders. Prehospital Emerg. Care 2013, 17, 241-260. [CrossRef]

47. Giesbrecht, G.G.; Jamieson, C.; Cahill, F. Cooling hyperthermic firefighters by immersing forearms and hands in 10 degrees c and 20 degrees c water. Aviat. Space Environ. Med. 2007, 78, 561-567. [PubMed] 
48. Kregel, K.C.; Seals, D.R.; Callister, R. Sympathetic nervous system activity during skin cooling in humans: Relationship to stimulus intensity and pain sensation. J. Physiol 1992, 454, 359-371. [CrossRef] [PubMed]

49. Racinais, S.; Moussay, S.; Nichols, D.; Travers, G.; Belfekih, T.; Schumacher, Y.O.; Periard, J.D. Core temperature up to $41.5^{\circ} \mathrm{C}$ during the uci road cycling world championships in the heat. Br. J. Sports Med. 2019, 53, 426-429. [CrossRef]

Publisher's Note: MDPI stays neutral with regard to jurisdictional claims in published maps and institutional affiliations.

(C) 2020 by the authors. Licensee MDPI, Basel, Switzerland. This article is an open access article distributed under the terms and conditions of the Creative Commons Attribution (CC BY) license (http://creativecommons.org/licenses/by/4.0/). 